\title{
Convergence theorems for mixed type asymptotically nonexpansive mappings
}

\author{
Weiping Guo', Yeol Je Cho ${ }^{2 *}$ and Wei Guo ${ }^{3}$
}

\author{
"Correspondence: yjcho@gsnu.ac.kr \\ ${ }^{2}$ Department of Mathematics \\ Education and the RINS College of \\ Education, Gyeongsang National \\ University, Chinju, 660-701, Korea \\ Full list of author information is \\ available at the end of the article
}

\begin{abstract}
In this paper, we introduce a new two-step iterative scheme of mixed type for two asymptotically nonexpansive self-mappings and two asymptotically nonexpansive nonself-mappings and prove strong and weak convergence theorems for the new two-step iterative scheme in uniformly convex Banach spaces.
\end{abstract}

Keywords: mixed type asymptotically nonexpansive mapping; strong and weak convergence; common fixed point; uniformly convex Banach space

\section{Introduction}

Let $K$ be a nonempty subset of a real normed linear space $E$. A mapping $T: K \rightarrow K$ is said to be asymptotically nonexpansive if there exists a sequence $\left\{k_{n}\right\} \subset[1, \infty)$ with $\lim _{n \rightarrow \infty} k_{n}=1$ such that

$$
\left\|T^{n} x-T^{n} y\right\| \leq k_{n}\|x-y\|
$$

for all $x, y \in K$ and $n \geq 1$.

In 1972, Goebel and Kirk [1] introduced the class of asymptotically nonexpansive self-mappings, which is an important generalization of the class of nonexpansive selfmappings, and proved that if $K$ is a nonempty closed convex subset of a real uniformly convex Banach space $E$ and $T$ is an asymptotically nonexpansive self-mapping of $K$, then $T$ has a fixed point.

Since then, some authors proved weak and strong convergence theorems for asymptotically nonexpansive self-mappings in Banach spaces (see [2-16]), which extend and improve the result of Goebel and Kirk in several ways.

Recently, Chidume et al. [10] introduced the concept of asymptotically nonexpansive nonself-mappings, which is a generalization of an asymptotically nonexpansive selfmapping, as follows.

Definition 1.1 [10] Let $K$ be a nonempty subset of a real normed linear space $E$. Let $P: E \rightarrow K$ be a nonexpansive retraction of $E$ onto $K$. A nonself-mapping $T: K \rightarrow E$ is said to be asymptotically nonexpansive if there exists a sequence $\left\{k_{n}\right\} \subset[1, \infty)$ with $k_{n} \rightarrow 1$ as $n \rightarrow \infty$ such that

$$
\left\|T(P T)^{n-1} x-T(P T)^{n-1} y\right\| \leq k_{n}\|x-y\|
$$

for all $x, y \in K$ and $n \geq 1$.

\section{Springer}

( 2012 Guo et al.; licensee Springer. This is an Open Access article distributed under the terms of the Creative Commons Attribution License (http://creativecommons.org/licenses/by/2.0), which permits unrestricted use, distribution, and reproduction in any medium, provided the original work is properly cited. 
Let $K$ be a nonempty closed convex subset of a real uniformly convex Banach space $E$. In 2003, also, Chidume et al. [10] studied the following iteration scheme:

$$
\left\{\begin{array}{l}
x_{1} \in K, \\
x_{n+1}=P\left(\left(1-\alpha_{n}\right) x_{n}+\alpha_{n} T_{1}\left(P T_{1}\right)^{n-1} x_{n}\right)
\end{array}\right.
$$

for each $n \geq 1$, where $\left\{\alpha_{n}\right\}$ is a sequence in $(0,1)$ and $P$ is a nonexpansive retraction of $E$ onto $K$, and proved some strong and weak convergence theorems for an asymptotically nonexpansive nonself-mapping.

In 2006, Wang [11] generalized the iteration process (1.3) as follows:

$$
\left\{\begin{array}{l}
x_{1} \in K \\
x_{n+1}=P\left(\left(1-\alpha_{n}\right) x_{n}+\alpha_{n} T_{1}\left(P T_{1}\right)^{n-1} y_{n}\right), \\
y_{n}=P\left(\left(1-\beta_{n}\right) x_{n}+\beta_{n} T_{2}\left(P T_{2}\right)^{n-1} x_{n}\right)
\end{array}\right.
$$

for each $n \geq 1$, where $T_{1}, T_{2}: K \rightarrow E$ are two asymptotically nonexpansive nonselfmappings and $\left\{\alpha_{n}\right\},\left\{\beta_{n}\right\}$ are real sequences in $[0,1)$, and proved some strong and weak convergence theorems for two asymptotically nonexpansive nonself-mappings. Recently, Guo and Guo [12] proved some new weak convergence theorems for the iteration process (1.4).

The purpose of this paper is to construct a new iteration scheme of mixed type for two asymptotically nonexpansive self-mappings and two asymptotically nonexpansive nonself-mappings and to prove some strong and weak convergence theorems for the new iteration scheme in uniformly convex Banach spaces.

\section{Preliminaries}

Let $E$ be a real Banach space, $K$ be a nonempty closed convex subset of $E$ and $P: E \rightarrow K$ be a nonexpansive retraction of $E$ onto $K$. Let $S_{1}, S_{2}: K \rightarrow K$ be two asymptotically nonexpansive self-mappings and $T_{1}, T_{2}: K \rightarrow E$ be two asymptotically nonexpansive nonselfmappings. Then we define the new iteration scheme of mixed type as follows:

$$
\left\{\begin{array}{l}
x_{1} \in K \\
x_{n+1}=P\left(\left(1-\alpha_{n}\right) S_{1}^{n} x_{n}+\alpha_{n} T_{1}\left(P T_{1}\right)^{n-1} y_{n}\right), \\
y_{n}=P\left(\left(1-\beta_{n}\right) S_{2}^{n} x_{n}+\beta_{n} T_{2}\left(P T_{2}\right)^{n-1} x_{n}\right)
\end{array}\right.
$$

for each $n \geq 1$, where $\left\{\alpha_{n}\right\},\left\{\beta_{n}\right\}$ are two sequences in $[0,1)$.

If $S_{1}$ and $S_{2}$ are the identity mappings, then the iterative scheme (2.1) reduces to the sequence (1.4).

We denote the set of common fixed points of $S_{1}, S_{2}, T_{1}$ and $T_{2}$ by $F=F\left(S_{1}\right) \cap F\left(S_{2}\right) \cap$ $F\left(T_{1}\right) \cap F\left(T_{2}\right)$ and denote the distance between a point $z$ and a set $A$ in $E$ by $d(z, A)=$ $\inf _{x \in A}\|z-x\|$.

Now, we recall some well-known concepts and results.

Let $E$ be a real Banach space, $E^{*}$ be the dual space of $E$ and $J: E \rightarrow 2^{E^{*}}$ be the normalized duality mapping defined by

$$
J(x)=\left\{f \in E^{*}:\langle x, f\rangle=\|x\|\|f\|,\|f\|=\|x\|\right\}
$$


for all $x \in E$, where $\langle\cdot, \cdot\rangle$ denotes duality pairing between $E$ and $E^{*}$. A single-valued normalized duality mapping is denoted by $j$.

A subset $K$ of a real Banach space $E$ is called a retract of $E[10]$ if there exists a continuous mapping $P: E \rightarrow K$ such that $P x=x$ for all $x \in K$. Every closed convex subset of a uniformly convex Banach space is a retract. A mapping $P: E \rightarrow E$ is called a retraction if $P^{2}=P$. It follows that if a mapping $P$ is a retraction, then $P y=y$ for all $y$ in the range of $P$.

A Banach space $E$ is said to satisfy Opial's condition [17] if, for any sequence $\left\{x_{n}\right\}$ of $E$, $x_{n} \rightarrow x$ weakly as $n \rightarrow \infty$ implies that

$$
\limsup _{n \rightarrow \infty}\left\|x_{n}-x\right\|<\limsup _{n \rightarrow \infty}\left\|x_{n}-y\right\|
$$

for all $y \in E$ with $y \neq x$.

A Banach space $E$ is said to have a Fréchet differentiable norm [18] if, for all $x \in U=\{x \in$ $E:\|x\|=1\}$

$$
\lim _{t \rightarrow 0} \frac{\|x+t y\|-\|x\|}{t}
$$

exists and is attained uniformly in $y \in U$.

A Banach space $E$ is said to have the Kadec-Klee property [19] if for every sequence $\left\{x_{n}\right\}$ in $E, x_{n} \rightarrow x$ weakly and $\left\|x_{n}\right\| \rightarrow\|x\|$, it follows that $x_{n} \rightarrow x$ strongly.

Let $K$ be a nonempty closed subset of a real Banach space $E$. A nonself-mapping $T: K \rightarrow$ $E$ is said to be semi-compact [11] if, for any sequence $\left\{x_{n}\right\}$ in $K$ such that $\left\|x_{n}-T x_{n}\right\| \rightarrow 0$ as $n \rightarrow \infty$, there exists a subsequence $\left\{x_{n_{j}}\right\}$ of $\left\{x_{n}\right\}$ such that $\left\{x_{n_{j}}\right\}$ converges strongly to some $x^{*} \in K$.

Lemma 2.1 [15] Let $\left\{a_{n}\right\},\left\{b_{n}\right\}$ and $\left\{c_{n}\right\}$ be three nonnegative sequences satisfying the following condition:

$$
a_{n+1} \leq\left(1+b_{n}\right) a_{n}+c_{n}
$$

for each $n \geq n_{0}$, where $n_{0}$ is some nonnegative integer, $\sum_{n=n_{0}}^{\infty} b_{n}<\infty$ and $\sum_{n=n_{0}}^{\infty} c_{n}<\infty$. Then $\lim _{n \rightarrow \infty} a_{n}$ exists.

Lemma 2.2 [8] Let E be a real uniformly convex Banach space and $0<p \leq t_{n} \leq q<1$ for each $n \geq 1$. Also, suppose that $\left\{x_{n}\right\}$ and $\left\{y_{n}\right\}$ are two sequences of $E$ such that

$$
\limsup _{n \rightarrow \infty}\left\|x_{n}\right\| \leq r, \quad \limsup _{n \rightarrow \infty}\left\|y_{n}\right\| \leq r, \quad \lim _{n \rightarrow \infty}\left\|t_{n} x_{n}+\left(1-t_{n}\right) y_{n}\right\|=r
$$

hold for some $r \geq 0$. Then $\lim _{n \rightarrow \infty}\left\|x_{n}-y_{n}\right\|=0$.

Lemma 2.3 [10] Let $E$ be a real uniformly convex Banach space, $K$ be a nonempty closed convex subset of $E$ and $T: K \rightarrow E$ be an asymptotically nonexpansive mapping with a sequence $\left\{k_{n}\right\} \subset[1, \infty)$ and $k_{n} \rightarrow 1$ as $n \rightarrow \infty$. Then $I-T$ is demiclosed at zero, i.e., if $x_{n} \rightarrow x$ weakly and $x_{n}-T x_{n} \rightarrow 0$ strongly, then $x \in F(T)$, where $F(T)$ is the set of fixed points of $T$. 
Lemma 2.4 [16] Let $X$ be a uniformly convex Banach space and $C$ be a convex subset of $X$. Then there exists a strictly increasing continuous convex function $\gamma:[0, \infty) \rightarrow[0, \infty)$ with $\gamma(0)=0$ such that, for each mapping $S: C \rightarrow C$ with a Lipschitz constant $L>0$,

$$
\|\alpha S x+(1-\alpha) S y-S[\alpha x+(1-\alpha) y]\| \leq L \gamma^{-1}\left(\|x-y\|-\frac{1}{L}\|S x-S y\|\right)
$$

for all $x, y \in C$ and $0<\alpha<1$.

Lemma 2.5 [16] Let $X$ be a uniformly convex Banach space such that its dual space $X^{*}$ has the Kadec-Klee property. Suppose $\left\{x_{n}\right\}$ is a bounded sequence and $f_{1}, f_{2} \in W_{w}\left(\left\{x_{n}\right\}\right)$ such that

$$
\lim _{n \rightarrow \infty}\left\|\alpha x_{n}+(1-\alpha) f_{1}-f_{2}\right\|
$$

exists for all $\alpha \in[0,1]$, where $W_{w}\left(\left\{x_{n}\right\}\right)$ denotes the set of all weak subsequential limits of $\left\{x_{n}\right\}$. Then $f_{1}=f_{2}$.

\section{Strong convergence theorems}

In this section, we prove strong convergence theorems for the iterative scheme given in (2.1) in uniformly convex Banach spaces.

Lemma 3.1 Let $E$ be a real uniformly convex Banach space and $K$ be a nonempty closed convex subset of $E$. Let $S_{1}, S_{2}: K \rightarrow K$ be two asymptotically nonexpansive self-mappings with $\left\{k_{n}^{(1)}\right\},\left\{k_{n}^{(2)}\right\} \subset[1, \infty)$ and $T_{1}, T_{2}: K \rightarrow E$ be two asymptotically nonexpansive nonselfmappings with $\left\{l_{n}^{(1)}\right\},\left\{l_{n}^{(2)}\right\} \subset[1, \infty)$ such that $\sum_{n=1}^{\infty}\left(k_{n}^{(i)}-1\right)<\infty$ and $\sum_{n=1}^{\infty}\left(l_{n}^{(i)}-1\right)<\infty$ for $i=1,2$, respectively, and $F=F\left(S_{1}\right) \cap F\left(S_{2}\right) \cap F\left(T_{1}\right) \cap F\left(T_{2}\right) \neq \emptyset$. Let $\left\{x_{n}\right\}$ be the sequence defined by (2.1), where $\left\{\alpha_{n}\right\}$ and $\left\{\beta_{n}\right\}$ are two real sequences in $[0,1)$. Then

(1) $\lim _{n \rightarrow \infty}\left\|x_{n}-q\right\|$ exists for any $q \in F$

(2) $\lim _{n \rightarrow \infty} d\left(x_{n}, F\right)$ exists.

Proof (1) Set $h_{n}=\max \left\{k_{n}^{(1)}, k_{n}^{(2)}, l_{n}^{(1)}, l_{n}^{(2)}\right\}$. For any $q \in F$, it follows from (2.1) that

$$
\begin{aligned}
\left\|y_{n}-q\right\| & \leq\left\|\left(1-\beta_{n}\right)\left(S_{2}^{n} x_{n}-q\right)+\beta_{n}\left(T_{2}\left(P T_{2}\right)^{n-1} x_{n}-q\right)\right\| \\
& \leq\left(1-\beta_{n}\right) h_{n}\left\|x_{n}-q\right\|+\beta_{n} h_{n}\left\|x_{n}-q\right\| \\
& =h_{n}\left\|x_{n}-q\right\|
\end{aligned}
$$

and so

$$
\begin{aligned}
\left\|x_{n+1}-q\right\| & \leq\left\|\left(1-\alpha_{n}\right)\left(S_{1}^{n} x_{n}-q\right)+\alpha_{n}\left(T_{1}\left(P T_{1}\right)^{n-1} y_{n}-q\right)\right\| \\
& \leq\left(1-\alpha_{n}\right) h_{n}\left\|x_{n}-q\right\|+\alpha_{n} h_{n}\left\|y_{n}-q\right\| \\
& \leq\left(1-\alpha_{n}\right) h_{n}^{2}\left\|x_{n}-q\right\|+\alpha_{n} h_{n}^{2}\left\|x_{n}-q\right\| \\
& =\left[1+\left(h_{n}^{2}-1\right)\right]\left\|x_{n}-q\right\| .
\end{aligned}
$$

Since $\sum_{n=1}^{\infty}\left(k_{n}^{(i)}-1\right)<\infty$ and $\sum_{n=1}^{\infty}\left(l_{n}^{(i)}-1\right)<\infty$ for $i=1,2$, we have $\sum_{n=1}^{\infty}\left(h_{n}^{2}-1\right)<\infty$. It follows from Lemma 2.1 that $\lim _{n \rightarrow \infty}\left\|x_{n}-q\right\|$ exists. 
(2) Taking the infimum over all $q \in F$ in (3.2), we have

$$
d\left(x_{n+1}, F\right) \leq\left[1+\left(h_{n}^{2}-1\right)\right] d\left(x_{n}, F\right)
$$

for each $n \geq 1$. It follows from $\sum_{n=1}^{\infty}\left(h_{n}^{2}-1\right)<\infty$ and Lemma 2.1 that the conclusion (2) holds. This completes the proof.

Lemma 3.2 Let $E$ be a real uniformly convex Banach space and $K$ be a nonempty closed convex subset of E. Let $S_{1}, S_{2}: K \rightarrow K$ be two asymptotically nonexpansive self-mappings with $\left\{k_{n}^{(1)}\right\},\left\{k_{n}^{(2)}\right\} \subset[1, \infty)$ and $T_{1}, T_{2}: K \rightarrow$ E be two asymptotically nonexpansive nonselfmappings with $\left\{l_{n}^{(1)}\right\},\left\{l_{n}^{(2)}\right\} \subset[1, \infty)$ such that $\sum_{n=1}^{\infty}\left(k_{n}^{(i)}-1\right)<\infty$ and $\sum_{n=1}^{\infty}\left(l_{n}^{(i)}-1\right)<\infty$ for $i=1,2$, respectively, and $F=F\left(S_{1}\right) \cap F\left(S_{2}\right) \cap F\left(T_{1}\right) \cap F\left(T_{2}\right) \neq \emptyset$. Let $\left\{x_{n}\right\}$ be the sequence defined by (2.1) and the following conditions hold:

(a) $\left\{\alpha_{n}\right\}$ and $\left\{\beta_{n}\right\}$ are two real sequences in $[\epsilon, 1-\epsilon]$ for some $\epsilon \in(0,1)$;

(b) $\left\|x-T_{i} y\right\| \leq\left\|S_{i} x-T_{i} y\right\|$ for all $x, y \in K$ and $i=1,2$.

Then $\lim _{n \rightarrow \infty}\left\|x_{n}-S_{i} x_{n}\right\|=\lim _{n \rightarrow \infty}\left\|x_{n}-T_{i} x_{n}\right\|=0$ for $i=1,2$.

Proof Set $h_{n}=\max \left\{k_{n}^{(1)}, k_{n}^{(2)}, l_{n}^{(1)}, l_{n}^{(2)}\right\}$. For any given $q \in F, \lim _{n \rightarrow \infty}\left\|x_{n}-q\right\|$ exists by Lemma 3.1. Now, we assume that $\lim _{n \rightarrow \infty}\left\|x_{n}-q\right\|=c$. It follows from (3.2) and $\sum_{n=1}^{\infty}\left(h_{n}^{2}-\right.$ 1) $<\infty$ that

$$
\lim _{n \rightarrow \infty}\left\|\left(1-\alpha_{n}\right)\left(S_{1}^{n} x_{n}-q\right)+\alpha_{n}\left(T_{1}\left(P T_{1}\right)^{n-1} y_{n}-q\right)\right\|=c
$$

and

$$
\limsup _{n \rightarrow \infty}\left\|S_{1}^{n} x_{n}-q\right\| \leq \limsup _{n \rightarrow \infty} k_{n}^{(1)}\left\|x_{n}-q\right\|=c .
$$

Taking limsup on both sides in (3.1), we obtain $\limsup _{n \rightarrow \infty}\left\|y_{n}-q\right\| \leq c$ and so

$$
\limsup _{n \rightarrow \infty}\left\|T_{1}\left(P T_{1}\right)^{n-1} y_{n}-q\right\| \leq \limsup _{n \rightarrow \infty} l_{n}^{(1)}\left\|y_{n}-q\right\| \leq c
$$

Using Lemma 2.2, we have

$$
\lim _{n \rightarrow \infty}\left\|S_{1}^{n} x_{n}-T_{1}\left(P T_{1}\right)^{n-1} y_{n}\right\|=0
$$

By the condition (b), it follows that

$$
\left\|x_{n}-T_{1}\left(P T_{1}\right)^{n-1} y_{n}\right\| \leq\left\|S_{1}^{n} x_{n}-T_{1}\left(P T_{1}\right)^{n-1} y_{n}\right\|
$$

and so, from (3.3), we have

$$
\lim _{n \rightarrow \infty}\left\|x_{n}-T_{1}\left(P T_{1}\right)^{n-1} y_{n}\right\|=0 .
$$

Since

$$
\begin{aligned}
\left\|x_{n}-q\right\| & \leq\left\|x_{n}-T_{1}\left(P T_{1}\right)^{n-1} y_{n}\right\|+\left\|T_{1}\left(P T_{1}\right)^{n-1} y_{n}-q\right\| \\
& \leq\left\|x_{n}-T_{1}\left(P T_{1}\right)^{n-1} y_{n}\right\|+l_{n}^{(1)}\left\|y_{n}-q\right\| .
\end{aligned}
$$


Taking liminf on both sides in the inequality above, we have

$$
\liminf _{n \rightarrow \infty}\left\|y_{n}-q\right\| \geq c
$$

by (3.4) and so

$$
\lim _{n \rightarrow \infty}\left\|y_{n}-q\right\|=c
$$

Using (3.1), we have

$$
\lim _{n \rightarrow \infty}\left\|\left(1-\beta_{n}\right)\left(S_{2}^{n} x_{n}-q\right)+\beta_{n}\left(T_{2}\left(P T_{2}\right)^{n-1} x_{n}-q\right)\right\|=c .
$$

In addition, we have

$$
\limsup _{n \rightarrow \infty}\left\|S_{2}^{n} x_{n}-q\right\| \leq \limsup _{n \rightarrow \infty} k_{n}^{(2)}\left\|x_{n}-q\right\|=c
$$

and

$$
\limsup _{n \rightarrow \infty}\left\|T_{2}\left(P T_{2}\right)^{n-1} x_{n}-q\right\| \leq \limsup _{n \rightarrow \infty} l_{n}^{(2)}\left\|x_{n}-q\right\|=c .
$$

It follows from Lemma 2.2 that

$$
\lim _{n \rightarrow \infty}\left\|S_{2}^{n} x_{n}-T_{2}\left(P T_{2}\right)^{n-1} x_{n}\right\|=0
$$

Now, we prove that

$$
\lim _{n \rightarrow \infty}\left\|x_{n}-T_{1} x_{n}\right\|=\lim _{n \rightarrow \infty}\left\|x_{n}-T_{2} x_{n}\right\|=0 .
$$

Indeed, since $\left\|x_{n}-T_{2}\left(P T_{2}\right)^{n-1} x_{n}\right\| \leq\left\|S_{2}^{n} x_{n}-T_{2}\left(P T_{2}\right)^{n-1} x_{n}\right\|$ by the condition (b). It follows from (3.5) that

$$
\lim _{n \rightarrow \infty}\left\|x_{n}-T_{2}\left(P T_{2}\right)^{n-1} x_{n}\right\|=0 \text {. }
$$

Since $S_{2}^{n} x_{n}=P\left(S_{2}^{n} x_{n}\right)$ and $P: E \rightarrow K$ is a nonexpansive retraction of $E$ onto $K$, we have

$$
\left\|y_{n}-S_{2}^{n} x_{n}\right\| \leq \beta_{n}\left\|S_{2}^{n} x_{n}-T_{2}\left(P T_{2}\right)^{n-1} x_{n}\right\|
$$

and so

$$
\lim _{n \rightarrow \infty}\left\|y_{n}-S_{2}^{n} x_{n}\right\|=0
$$

Furthermore, we have

$$
\left\|y_{n}-x_{n}\right\| \leq\left\|y_{n}-S_{2}^{n} x_{n}\right\|+\left\|S_{2}^{n} x_{n}-T_{2}\left(P T_{2}\right)^{n-1} x_{n}\right\|+\left\|T_{2}\left(P T_{2}\right)^{n-1} x_{n}-x_{n}\right\| .
$$


Thus it follows from (3.5), (3.6) and (3.7) that

$$
\lim _{n \rightarrow \infty}\left\|x_{n}-y_{n}\right\|=0
$$

Since $\left\|x_{n}-T_{1}\left(P T_{1}\right)^{n-1} x_{n}\right\| \leq\left\|S_{1}^{n} x_{n}-T_{1}\left(P T_{1}\right)^{n-1} x_{n}\right\|$ by the condition (b) and

$$
\begin{aligned}
& \left\|S_{1}^{n} x_{n}-T_{1}\left(P T_{1}\right)^{n-1} x_{n}\right\| \\
& \quad \leq\left\|S_{1}^{n} x_{n}-T_{1}\left(P T_{1}\right)^{n-1} y_{n}\right\|+\left\|T_{1}\left(P T_{1}\right)^{n-1} y_{n}-T_{1}\left(P T_{1}\right)^{n-1} x_{n}\right\| \\
& \quad \leq\left\|S_{1}^{n} x_{n}-T_{1}\left(P T_{1}\right)^{n-1} y_{n}\right\|+l_{n}^{(1)}\left\|y_{n}-x_{n}\right\| .
\end{aligned}
$$

Using (3.3) and (3.8), we have

$$
\lim _{n \rightarrow \infty}\left\|S_{1}^{n} x_{n}-T_{1}\left(P T_{1}\right)^{n-1} x_{n}\right\|=0
$$

and

$$
\lim _{n \rightarrow \infty}\left\|x_{n}-T_{1}\left(P T_{1}\right)^{n-1} x_{n}\right\|=0
$$

It follows from

$$
\begin{aligned}
\left\|x_{n+1}-S_{1}^{n} x_{n}\right\| & =\left\|P\left[\left(1-\alpha_{n}\right) S_{1}^{n} x_{n}+\alpha_{n} T_{1}\left(P T_{1}\right)^{n-1} y_{n}\right]-P\left(S_{1}^{n} x_{n}\right)\right\| \\
& \leq \alpha_{n}\left\|S_{1}^{n} x_{n}-T_{1}\left(P T_{1}\right)^{n-1} y_{n}\right\|
\end{aligned}
$$

and (3.3) that

$$
\lim _{n \rightarrow \infty}\left\|x_{n+1}-S_{1}^{n} x_{n}\right\|=0
$$

In addition, we have

$$
\left\|x_{n+1}-T_{1}\left(P T_{1}\right)^{n-1} y_{n}\right\| \leq\left\|x_{n+1}-S_{1}^{n} x_{n}\right\|+\left\|S_{1}^{n} x_{n}-T_{1}\left(P T_{1}\right)^{n-1} y_{n}\right\| .
$$

Using (3.3) and (3.11), we obtain that

$$
\lim _{n \rightarrow \infty}\left\|x_{n+1}-T_{1}\left(P T_{1}\right)^{n-1} y_{n}\right\|=0 .
$$

Thus, using (3.9), (3.10) and the inequality

$$
\left\|S_{1}^{n} x_{n}-x_{n}\right\| \leq\left\|S_{1}^{n} x_{n}-T_{1}\left(P T_{1}\right)^{n-1} x_{n}\right\|+\left\|T_{1}\left(P T_{1}\right)^{n-1} x_{n}-x_{n}\right\|,
$$

we have $\lim _{n \rightarrow \infty}\left\|S_{1}^{n} x_{n}-x_{n}\right\|=0$. It follows from (3.6) and the inequality

$$
\left\|S_{1}^{n} x_{n}-T_{2}\left(P T_{2}\right)^{n-1} x_{n}\right\| \leq\left\|S_{1}^{n} x_{n}-x_{n}\right\|+\left\|x_{n}-T_{2}\left(P T_{2}\right)^{n-1} x_{n}\right\|
$$

that

$$
\lim _{n \rightarrow \infty}\left\|S_{1}^{n} x_{n}-T_{2}\left(P T_{2}\right)^{n-1} x_{n}\right\|=0
$$


Since

$$
\left\|x_{n+1}-T_{2}\left(P T_{2}\right)^{n-1} y_{n}\right\| \leq\left\|x_{n+1}-S_{1}^{n} x_{n}\right\|+\left\|S_{1}^{n} x_{n}-T_{2}\left(P T_{2}\right)^{n-1} x_{n}\right\|+l_{n}^{(2)}\left\|x_{n}-y_{n}\right\|,
$$

from (3.8), (3.11) and (3.13), it follows that

$$
\lim _{n \rightarrow \infty}\left\|x_{n+1}-T_{2}\left(P T_{2}\right)^{n-1} y_{n}\right\|=0
$$

Again, since $\left(P T_{i}\right)\left(P T_{i}\right)^{n-2} y_{n-1}, x_{n} \in K$ for $i=1,2$ and $T_{1}, T_{2}$ are two asymptotically nonexpansive nonself-mappings, we have

$$
\begin{aligned}
& \left\|T_{i}\left(P T_{i}\right)^{n-1} y_{n-1}-T_{i} x_{n}\right\| \\
& \quad=\left\|T_{i}\left[\left(P T_{i}\right)\left(P T_{i}\right)^{n-2} y_{n-1}\right]-T_{i}\left(P x_{n}\right)\right\| \\
& \quad \leq \max \left\{l_{1}^{(1)}, l_{1}^{(2)}\right\}\left\|\left(P T_{i}\right)\left(P T_{i}\right)^{n-2} y_{n-1}-P x_{n}\right\| \\
& \quad \leq \max \left\{l_{1}^{(1)}, l_{1}^{(2)}\right\}\left\|T_{i}\left(P T_{i}\right)^{n-2} y_{n-1}-x_{n}\right\|
\end{aligned}
$$

for $i=1,2$. It follows from (3.12), (3.14) and (3.15) that

$$
\lim _{n \rightarrow \infty}\left\|T_{i}\left(P T_{i}\right)^{n-1} y_{n-1}-T_{i} x_{n}\right\|=0
$$

for $i=1,2$. Moreover, we have

$$
\left\|x_{n+1}-y_{n}\right\| \leq\left\|x_{n+1}-T_{1}\left(P T_{1}\right)^{n-1} y_{n}\right\|+\left\|T_{1}\left(P T_{1}\right)^{n-1} y_{n}-x_{n}\right\|+\left\|x_{n}-y_{n}\right\| .
$$

Using (3.4), (3.8) and (3.12), we have

$$
\lim _{n \rightarrow \infty}\left\|x_{n+1}-y_{n}\right\|=0
$$

In addition, we have

$$
\begin{aligned}
\left\|x_{n}-T_{i} x_{n}\right\| \leq & \left\|x_{n}-T_{i}\left(P T_{i}\right)^{n-1} x_{n}\right\|+\left\|T_{i}\left(P T_{i}\right)^{n-1} x_{n}-T_{i}\left(P T_{i}\right)^{n-1} y_{n-1}\right\| \\
& +\left\|T_{i}\left(P T_{i}\right)^{n-1} y_{n-1}-T_{i} x_{n}\right\| \\
\leq & \left\|x_{n}-T_{i}\left(P T_{i}\right)^{n-1} x_{n}\right\|+\max \left\{\sup _{n \geq 1} l_{n}^{(1)}, \sup _{n \geq 1} l_{n}^{(2)}\right\}\left\|x_{n}-y_{n-1}\right\| \\
& +\left\|T_{i}\left(P T_{i}\right)^{n-1} y_{n-1}-T_{i} x_{n}\right\|
\end{aligned}
$$

for $i=1,2$. Thus it follows from (3.6), (3.10), (3.16) and (3.17) that

$$
\lim _{n \rightarrow \infty}\left\|x_{n}-T_{1} x_{n}\right\|=\lim _{n \rightarrow \infty}\left\|x_{n}-T_{2} x_{n}\right\|=0 .
$$

Finally, we prove that

$$
\lim _{n \rightarrow \infty}\left\|x_{n}-S_{1} x_{n}\right\|=\lim _{n \rightarrow \infty}\left\|x_{n}-S_{2} x_{n}\right\|=0 .
$$


In fact, by the condition (b), we have

$$
\begin{aligned}
\left\|x_{n}-S_{i} x_{n}\right\| & \leq\left\|x_{n}-T_{i}\left(P T_{i}\right)^{n-1} x_{n}\right\|+\left\|S_{i} x_{n}-T_{i}\left(P T_{i}\right)^{n-1} x_{n}\right\| \\
& \leq\left\|x_{n}-T_{i}\left(P T_{i}\right)^{n-1} x_{n}\right\|+\left\|S_{i}^{n} x_{n}-T_{i}\left(P T_{i}\right)^{n-1} x_{n}\right\|
\end{aligned}
$$

for $i=1,2$. Thus it follows from (3.5), (3.6), (3.9) and (3.10) that

$$
\lim _{n \rightarrow \infty}\left\|x_{n}-S_{1} x_{n}\right\|=\lim _{n \rightarrow \infty}\left\|x_{n}-S_{2} x_{n}\right\|=0
$$

This completes the proof.

Now, we find two mappings, $S_{1}=S_{2}=S$ and $T_{1}=T_{2}=T$, satisfying the condition (b) in Lemma 3.2 as follows.

Example 3.1 [20] Let $\mathbb{R}$ be the real line with the usual norm $|\cdot|$ and let $K=[-1,1]$. Define two mappings $S, T: K \rightarrow K$ by

$$
T x= \begin{cases}-2 \sin \frac{x}{2}, & \text { if } x \in[0,1], \\ 2 \sin \frac{x}{2}, & \text { if } x \in[-1,0),\end{cases}
$$

and

$$
S x= \begin{cases}x, & \text { if } x \in[0,1], \\ -x, & \text { if } x \in[-1,0) .\end{cases}
$$

Now, we show that $T$ is nonexpansive. In fact, if $x, y \in[0,1]$ or $x, y \in[-1,0)$, then we have

$$
|T x-T y|=2\left|\sin \frac{x}{2}-\sin \frac{y}{2}\right| \leq|x-y|
$$

If $x \in[0,1]$ and $y \in[-1,0)$ or $x \in[-1,0)$ and $y \in[0,1]$, then we have

$$
\begin{aligned}
|T x-T y| & =2\left|\sin \frac{x}{2}+\sin \frac{y}{2}\right| \\
& =4\left|\sin \frac{x+y}{4} \cos \frac{x-y}{4}\right| \\
& \leq|x+y| \\
& \leq|x-y| .
\end{aligned}
$$

This implies that $T$ is nonexpansive and so $T$ is an asymptotically nonexpansive mapping with $k_{n}=1$ for each $n \geq 1$. Similarly, we can show that $S$ is an asymptotically nonexpansive mapping with $l_{n}=1$ for each $n \geq 1$.

Next, we show that two mappings $S, T$ satisfy the condition (b) in Lemma 3.2. For this, we consider the following cases: 
Case 1. Let $x, y \in[0,1]$. Then we have

$$
|x-T y|=\left|x+2 \sin \frac{y}{2}\right|=|S x-T y| .
$$

Case 2. Let $x, y \in[-1,0)$. Then we have

$$
|x-T y|=\left|x-2 \sin \frac{y}{2}\right| \leq\left|-x-2 \sin \frac{y}{2}\right|=|S x-T y| .
$$

Case 3. Let $x \in[-1,0)$ and $y \in[0,1]$. Then we have

$$
|x-T y|=\left|x+2 \sin \frac{y}{2}\right| \leq\left|-x+2 \sin \frac{y}{2}\right|=|S x-T y| .
$$

Case 4. Let $x \in[0,1]$ and $y \in[-1,0)$. Then we have

$$
|x-T y|=\left|x-2 \sin \frac{y}{2}\right|=|S x-T y| .
$$

Therefore, the condition (b) in Lemma 3.2 is satisfied.

Theorem 3.1 Under the assumptions of Lemma 3.2, if one of $S_{1}, S_{2}, T_{1}$ and $T_{2}$ is completely continuous, then the sequence $\left\{x_{n}\right\}$ defined by (2.1) converges strongly to a common fixed point of $S_{1}, S_{2}, T_{1}$ and $T_{2}$.

Proof Without loss of generality, we can assume that $S_{1}$ is completely continuous. Since $\left\{x_{n}\right\}$ is bounded by Lemma 3.1, there exists a subsequence $\left\{S_{1} x_{n_{j}}\right\}$ of $\left\{S_{1} x_{n}\right\}$ such that $\left\{S_{1} x_{n_{j}}\right\}$ converges strongly to some $q^{*}$. Moreover, we know that

$$
\lim _{j \rightarrow \infty}\left\|x_{n_{j}}-S_{1} x_{n_{j}}\right\|=\lim _{j \rightarrow \infty}\left\|x_{n_{j}}-S_{2} x_{n_{j}}\right\|=0
$$

and

$$
\lim _{j \rightarrow \infty}\left\|x_{n_{j}}-T_{1} x_{n_{j}}\right\|=\lim _{j \rightarrow \infty}\left\|x_{n_{j}}-T_{2} x_{n_{j}}\right\|=0
$$

by Lemma 3.2, which imply that

$$
\left\|x_{n_{j}}-q^{*}\right\| \leq\left\|x_{n_{j}}-S_{1} x_{n_{j}}\right\|+\left\|S_{1} x_{n_{j}}-q^{*}\right\| \rightarrow 0
$$

as $j \rightarrow \infty$ and so $x_{n_{j}} \rightarrow q^{*} \in K$. Thus, by the continuity of $S_{1}, S_{2}, T_{1}$ and $T_{2}$, we have

$$
\left\|q^{*}-S_{i} q^{*}\right\|=\lim _{j \rightarrow \infty}\left\|x_{n_{j}}-S_{i} x_{n_{j}}\right\|=0
$$

and

$$
\left\|q^{*}-T_{i} q^{*}\right\|=\lim _{j \rightarrow \infty}\left\|x_{n_{j}}-T_{i} x_{n_{j}}\right\|=0
$$

for $i=1,2$. Thus it follows that $q^{*} \in F\left(S_{1}\right) \cap F\left(S_{2}\right) \cap F\left(T_{1}\right) \cap F\left(T_{2}\right)$. Furthermore, since 
$\lim _{n \rightarrow \infty}\left\|x_{n}-q^{*}\right\|$ exists by Lemma 3.1, we have $\lim _{n \rightarrow \infty}\left\|x_{n}-q^{*}\right\|=0$. This completes the proof.

Theorem 3.2 Under the assumptions of Lemma 3.2, if one of $S_{1}, S_{2}, T_{1}$ and $T_{2}$ is semicompact, then the sequence $\left\{x_{n}\right\}$ defined by (2.1) converges strongly to a common fixed point of $S_{1}, S_{2}, T_{1}$ and $T_{2}$.

Proof Since $\lim _{n \rightarrow \infty}\left\|x_{n}-S_{i} x_{n}\right\|=\lim _{n \rightarrow \infty}\left\|x_{n}-T_{i} x_{n}\right\|=0$ for $i=1,2$ by Lemma 3.2 and one of $S_{1}, S_{2}, T_{1}$ and $T_{2}$ is semi-compact, there exists a subsequence $\left\{x_{n_{j}}\right\}$ of $\left\{x_{n}\right\}$ such that $\left\{x_{n_{j}}\right\}$ converges strongly to some $q^{*} \in K$. Moreover, by the continuity of $S_{1}, S_{2}, T_{1}$ and $T_{2}$, we have $\left\|q^{*}-S_{i} q^{*}\right\|=\lim _{j \rightarrow \infty}\left\|x_{n_{j}}-S_{i} x_{n_{j}}\right\|=0$ and $\left\|q^{*}-T_{i} q^{*}\right\|=\lim _{j \rightarrow \infty}\left\|x_{n_{j}}-T_{i} x_{n_{j}}\right\|=0$ for $i=1,2$. Thus it follows that $q^{*} \in F\left(S_{1}\right) \cap F\left(S_{2}\right) \cap F\left(T_{1}\right) \cap F\left(T_{2}\right)$. Since $\lim _{n \rightarrow \infty}\left\|x_{n}-q^{*}\right\|$ exists by Lemma 3.1, we have $\lim _{n \rightarrow \infty}\left\|x_{n}-q^{*}\right\|=0$. This completes the proof.

Theorem 3.3 Under the assumptions of Lemma 3.2, if there exists a nondecreasing function $f:[0, \infty) \rightarrow[0, \infty)$ with $f(0)=0$ and $f(r)>0$ for all $r \in(0, \infty)$ such that

$$
f(d(x, F)) \leq\left\|x-S_{1} x\right\|+\left\|x-S_{2} x\right\|+\left\|x-T_{1} x\right\|+\left\|x-T_{2} x\right\|
$$

for all $x \in K$, where $F=F\left(S_{1}\right) \cap F\left(S_{2}\right) \cap F\left(T_{1}\right) \cap F\left(T_{2}\right)$, then the sequence $\left\{x_{n}\right\}$ defined by (2.1) converges strongly to a common fixed point of $S_{1}, S_{2}, T_{1}$ and $T_{2}$.

Proof Since $\lim _{n \rightarrow \infty}\left\|x_{n}-S_{i} x_{n}\right\|=\lim _{n \rightarrow \infty}\left\|x_{n}-T_{i} x_{n}\right\|=0$ for $i=1,2$ by Lemma 3.2, we have $\lim _{n \rightarrow \infty} f\left(d\left(x_{n}, F\right)\right)=0$. Since $f:[0, \infty) \rightarrow[0, \infty)$ is a nondecreasing function satisfying $f(0)=0, f(r)>0$ for all $r \in(0, \infty)$ and $\lim _{n \rightarrow \infty} d\left(x_{n}, F\right)$ exists by Lemma 3.1, we have $\lim _{n \rightarrow \infty} d\left(x_{n}, F\right)=0$.

Now, we show that $\left\{x_{n}\right\}$ is a Cauchy sequence in $K$. In fact, from (3.2), we have

$$
\left\|x_{n+1}-q\right\| \leq\left[1+\left(h_{n}^{2}-1\right)\right]\left\|x_{n}-q\right\|
$$

for each $n \geq 1$, where $h_{n}=\max \left\{k_{n}^{(1)}, k_{n}^{(2)}, l_{n}^{(1)}, l_{n}^{(2)}\right\}$ and $q \in F$. For any $m, n, m>n \geq 1$, we have

$$
\begin{aligned}
\left\|x_{m}-q\right\| & \leq\left[1+\left(h_{m-1}^{2}-1\right)\right]\left\|x_{m-1}-q\right\| \\
& \leq e^{h_{m-1}^{2}-1}\left\|x_{m-1}-q\right\| \\
& \leq e^{h_{m-1}^{2}-1} e^{h_{m-2}^{2}-1}\left\|x_{m-2}-q\right\| \\
& \leq \cdots \\
& \leq e^{\sum_{i=n}^{m-1}\left(h_{i}^{2}-1\right)}\left\|x_{n}-q\right\| \\
& \leq M\left\|x_{n}-q\right\|
\end{aligned}
$$

where $M=e^{\sum_{i=1}^{\infty}\left(h_{i}^{2}-1\right)}$. Thus, for any $q \in F$, we have

$$
\begin{aligned}
\left\|x_{n}-x_{m}\right\| & \leq\left\|x_{n}-q\right\|+\left\|x_{m}-q\right\| \\
& \leq(1+M)\left\|x_{n}-q\right\| .
\end{aligned}
$$


Taking the infimum over all $q \in F$, we obtain

$$
\left\|x_{n}-x_{m}\right\| \leq(1+M) d\left(x_{n}, F\right) .
$$

Thus it follows from $\lim _{n \rightarrow \infty} d\left(x_{n}, F\right)=0$ that $\left\{x_{n}\right\}$ is a Cauchy sequence. Since $K$ is a closed subset of $E$, the sequence $\left\{x_{n}\right\}$ converges strongly to some $q^{*} \in K$. It is easy to prove that $F\left(S_{1}\right), F\left(S_{2}\right), F\left(T_{1}\right)$ and $F\left(T_{2}\right)$ are all closed and so $F$ is a closed subset of $K$. Since $\lim _{n \rightarrow \infty} d\left(x_{n}, F\right)=0, q^{*} \in F$, the sequence $\left\{x_{n}\right\}$ converges strongly to a common fixed point of $S_{1}, S_{2}, T_{1}$ and $T_{2}$. This completes the proof.

\section{Weak convergence theorems}

In this section, we prove weak convergence theorems for the iterative scheme defined by (2.1) in uniformly convex Banach spaces.

Lemma 4.1 Under the assumptions of Lemma 3.1, for all $q_{1}, q_{2} \in F=F\left(S_{1}\right) \cap F\left(S_{2}\right) \cap F\left(T_{1}\right) \cap$ $F\left(T_{2}\right)$, the limit

$$
\lim _{n \rightarrow \infty}\left\|t x_{n}+(1-t) q_{1}-q_{2}\right\|
$$

exists for all $t \in[0,1]$, where $\left\{x_{n}\right\}$ is the sequence defined by $(2.1)$.

Proof Set $a_{n}(t)=\left\|t x_{n}+(1-t) q_{1}-q_{2}\right\|$. Then $\lim _{n \rightarrow \infty} a_{n}(0)=\left\|q_{1}-q_{2}\right\|$ and, from Lemma 3.1, $\lim _{n \rightarrow \infty} a_{n}(1)=\lim _{n \rightarrow \infty}\left\|x_{n}-q_{2}\right\|$ exists. Thus it remains to prove Lemma 4.1 for any $t \in$ $(0,1)$.

Define the mapping $G_{n}: K \rightarrow K$ by

$$
G_{n} x=P\left[\left(1-\alpha_{n}\right) S_{1}^{n} x+\alpha_{n} T_{1}\left(P T_{1}\right)^{n-1} P\left(\left(1-\beta_{n}\right) S_{2}^{n} x+\beta_{n} T_{2}\left(P T_{2}\right)^{n-1} x\right)\right]
$$

for all $x \in K$. It is easy to prove that

$$
\left\|G_{n} x-G_{n} y\right\| \leq h_{n}^{4}\|x-y\|
$$

for all $x, y \in K$, where $h_{n}=\max \left\{k_{n}^{(1)}, k_{n}^{(2)}, l_{n}^{(1)}, l_{n}^{(2)}\right\}$. Letting $h_{n}=1+v_{n}$, it follows from $1 \leq$ $\prod_{j=n}^{\infty} h_{j}^{4} \leq e^{4 \sum_{j=n}^{\infty} v_{j}}$ and $\sum_{n=1}^{\infty} v_{n}<\infty$ that $\lim _{n \rightarrow \infty} \prod_{j=n}^{\infty} h_{j}^{4}=1$. Setting

$$
S_{n, m}=G_{n+m-1} G_{n+m-2} \cdots G_{n}
$$

for each $m \geq 1$, from (4.1) and (4.2), it follows that

$$
\left\|S_{n, m} x-S_{n, m} y\right\| \leq\left(\prod_{j=n}^{n+m-1} h_{j}^{4}\right)\|x-y\|
$$

for all $x, y \in K$ and $S_{n, m} x_{n}=x_{n+m}, S_{n, m} q=q$ for any $q \in F$. Let

$$
b_{n, m}=\left\|t S_{n, m} x_{n}+(1-t) S_{n, m} q_{1}-S_{n, m}\left(t x_{n}+(1-t) q_{1}\right)\right\| .
$$


Then, using (4.3) and Lemma 2.4, we have

$$
\begin{aligned}
b_{n, m} & \leq\left(\prod_{j=n}^{n+m-1} h_{j}^{4}\right) \gamma^{-1}\left(\left\|x_{n}-q_{1}\right\|-\left(\prod_{j=n}^{n+m-1} h_{j}^{4}\right)^{-1}\left\|S_{n, m} x_{n}-S_{n, m} q_{1}\right\|\right) \\
& \leq\left(\prod_{j=n}^{\infty} h_{j}^{4}\right) \gamma^{-1}\left(\left\|x_{n}-q_{1}\right\|-\left(\prod_{j=n}^{\infty} h_{j}^{4}\right)^{-1}\left\|x_{n+m}-q_{1}\right\|\right) .
\end{aligned}
$$

It follows from Lemma 3.1 and $\lim _{n \rightarrow \infty} \prod_{j=n}^{\infty} h_{j}^{4}=1$ that $\lim _{n \rightarrow \infty} b_{n, m}=0$ uniformly for all $m$. Observe that

$$
\begin{aligned}
a_{n+m}(t) & \leq\left\|S_{n, m}\left(t x_{n}+(1-t) q_{1}\right)-q_{2}\right\|+b_{n, m} \\
& =\left\|S_{n, m}\left(t x_{n}+(1-t) q_{1}\right)-S_{n, m} q_{2}\right\|+b_{n, m} \\
& \leq\left(\prod_{j=n}^{n+m-1} h_{j}^{4}\right)\left\|t x_{n}+(1-t) q_{1}-q_{2}\right\|+b_{n, m} \\
& \leq\left(\prod_{j=n}^{\infty} h_{j}^{4}\right) a_{n}(t)+b_{n, m} .
\end{aligned}
$$

Thus we have $\limsup _{n \rightarrow \infty} a_{n}(t) \leq \liminf _{n \rightarrow \infty} a_{n}(t)$, that is, $\lim _{n \rightarrow \infty}\left\|t x_{n}+(1-t) q_{1}-q_{2}\right\|$ exists for all $t \in(0,1)$. This completes the proof.

Lemma 4.2 Under the assumptions of Lemma 3.1, if E has a Fréchet differentiable norm, then, for all $q_{1}, q_{2} \in F=F\left(S_{1}\right) \cap F\left(S_{2}\right) \cap F\left(T_{1}\right) \cap F\left(T_{2}\right)$, the limit

$$
\lim _{n \rightarrow \infty}\left\langle x_{n}, j\left(q_{1}-q_{2}\right)\right\rangle
$$

exists, where $\left\{x_{n}\right\}$ is the sequence defined by (2.1). Furthermore, if $W_{w}\left(\left\{x_{n}\right\}\right)$ denotes the set of all weak subsequential limits of $\left\{x_{n}\right\}$, then $\left\langle x^{*}-y^{*}, j\left(q_{1}-q_{2}\right)\right\rangle=0$ for all $q_{1}, q_{2} \in F$ and $x^{*}, y^{*} \in W_{w}\left(\left\{x_{n}\right\}\right)$.

Proof This follows basically as in the proof of Lemma 3.2 of [12] using Lemma 4.1 instead of Lemma 3.1 of [12].

Theorem 4.1 Under the assumptions of Lemma 3.2, if E has a Fréchet differentiable norm, then the sequence $\left\{x_{n}\right\}$ defined by (2.1) converges weakly to a common fixed point of $S_{1}, S_{2}$, $T_{1}$ and $T_{2}$.

Proof Since $E$ is a uniformly convex Banach space and the sequence $\left\{x_{n}\right\}$ is bounded by Lemma 3.1, there exists a subsequence $\left\{x_{n_{k}}\right\}$ of $\left\{x_{n}\right\}$ which converges weakly to some $q \in K$. By Lemma 3.2, we have

$$
\lim _{k \rightarrow \infty}\left\|x_{n_{k}}-S_{i} x_{n_{k}}\right\|=\lim _{k \rightarrow \infty}\left\|x_{n_{k}}-T_{i} x_{n_{k}}\right\|=0
$$

for $i=1$, 2. It follows from Lemma 2.3 that $q \in F=F\left(S_{1}\right) \cap F\left(S_{2}\right) \cap F\left(T_{1}\right) \cap F\left(T_{2}\right)$. 
Now, we prove that the sequence $\left\{x_{n}\right\}$ converges weakly to $q$. Suppose that there exists a subsequence $\left\{x_{m_{j}}\right\}$ of $\left\{x_{n}\right\}$ such that $\left\{x_{m_{j}}\right\}$ converges weakly to some $q_{1} \in K$. Then, by the same method given above, we can also prove that $q_{1} \in F$. So, $q, q_{1} \in F \cap W_{w}\left(\left\{x_{n}\right\}\right)$. It follows from Lemma 4.2 that

$$
\left\|q-q_{1}\right\|^{2}=\left\langle q-q_{1}, j\left(q-q_{1}\right)\right\rangle=0 .
$$

Therefore, $q_{1}=q$, which shows that the sequence $\left\{x_{n}\right\}$ converges weakly to $q$. This completes the proof.

Theorem 4.2 Under the assumptions of Lemma 3.2, if the dual space $E^{*}$ of $E$ has the Kadec-Klee property, then the sequence $\left\{x_{n}\right\}$ defined by (2.1) converges weakly to a common fixed point of $S_{1}, S_{2}, T_{1}$ and $T_{2}$.

Proof Using the same method given in Theorem 4.1, we can prove that there exists a subsequence $\left\{x_{n_{k}}\right\}$ of $\left\{x_{n}\right\}$ which converges weakly to some $q \in F=F\left(S_{1}\right) \cap F\left(S_{2}\right) \cap F\left(T_{1}\right) \cap F\left(T_{2}\right)$.

Now, we prove that the sequence $\left\{x_{n}\right\}$ converges weakly to $q$. Suppose that there exists a subsequence $\left\{x_{m_{j}}\right\}$ of $\left\{x_{n}\right\}$ such that $\left\{x_{m_{j}}\right\}$ converges weakly to some $q^{*} \in K$. Then, as for $q$, we have $q^{*} \in F$. It follows from Lemma 4.1 that the limit

$$
\lim _{n \rightarrow \infty}\left\|t x_{n}+(1-t) q-q^{*}\right\|
$$

exists for all $t \in[0,1]$. Again, since $q, q^{*} \in W_{w}\left(\left\{x_{n}\right\}\right), q^{*}=q$ by Lemma 2.5 . This shows that the sequence $\left\{x_{n}\right\}$ converges weakly to $q$. This completes the proof.

Theorem 4.3 Under the assumptions of Lemma 3.2, if E satisfies Opial's condition, then the sequence $\left\{x_{n}\right\}$ defined by (2.1) converges weakly to a common fixed point of $S_{1}, S_{2}, T_{1}$ and $T_{2}$.

Proof Using the same method as given in Theorem 4.1, we can prove that there exists a subsequence $\left\{x_{n_{k}}\right\}$ of $\left\{x_{n}\right\}$ which converges weakly to some $q \in F=F\left(S_{1}\right) \cap F\left(S_{2}\right) \cap F\left(T_{1}\right) \cap$ $F\left(T_{2}\right)$.

Now, we prove that the sequence $\left\{x_{n}\right\}$ converges weakly to $q$. Suppose that there exists a subsequence $\left\{x_{m_{j}}\right\}$ of $\left\{x_{n}\right\}$ such that $\left\{x_{m_{j}}\right\}$ converges weakly to some $\bar{q} \in K$ and $\bar{q} \neq q$. Then, as for $q$, we have $\bar{q} \in F$. Using Lemma 3.1, we have the following two limits exist:

$$
\lim _{n \rightarrow \infty}\left\|x_{n}-q\right\|=c, \quad \lim _{n \rightarrow \infty}\left\|x_{n}-\bar{q}\right\|=c_{1} .
$$

Thus, by Opial's condition, we have

$$
c=\limsup _{k \rightarrow \infty}\left\|x_{n_{k}}-q\right\|<\limsup _{k \rightarrow \infty}\left\|x_{n_{k}}-\bar{q}\right\|=\limsup _{j \rightarrow \infty}\left\|x_{m_{j}}-\bar{q}\right\|<\limsup _{j \rightarrow \infty}\left\|x_{m_{j}}-q\right\|=c,
$$

which is a contradiction and so $q=\bar{q}$. This shows that the sequence $\left\{x_{n}\right\}$ converges weakly to $q$. This completes the proof. 


\section{Competing interests}

The authors declare that they have no competing interests.

\section{Authors' contributions}

All authors read and approved the final manuscript.

\section{Author details}

${ }^{1}$ School of Mathematics and Physics, Suzhou University of Science and Technology, Suzhou, Jiangsu 215009, P.R. China.

${ }^{2}$ Department of Mathematics Education and the RINS College of Education, Gyeongsang National University, Chinju, 660-701, Korea. ${ }^{3}$ Department of Aerospace Engineering and Mechanics, University of Minnesota, Twin Cities, Minneapolis, MN 55455, USA.

\section{Acknowledgements}

The project was supported by the National Natural Science Foundation of China (Grant Number: 11271282) and the second author was supported by the Basic Science Research Program through the National Research Foundation of Korea (NRF) funded by the Ministry of Education, Science and Technology (Grant Number: 2012-0008170).

\section{Received: 27 April 2012 Accepted: 16 November 2012 Published: 11 December 2012}

\section{References}

1. Goebel, K, Kirk, WA: A fixed point theorem for asymptotically nonexpansive mapping. Proc. Am. Math. Soc. 35, 171-174 (1972)

2. Chang, SS, Cho, YJ, Zhou, HY: Demi-closed principle and weak convergence problems for asymptotically nonexpansive mappings. J. Korean Math. Soc. 38, 1245-1260 (2001)

3. Chang, SS, Tan, KK, Lee, HWJ, Chan, CK: On the convergence of implicit iteration process with error for a finite family of asymptotically nonexpansive mappings. J. Math. Anal. Appl. 313, 273-283 (2006)

4. Cho, YJ, Kang, Jl, Zhou, HY: Approximating common fixed points of asymptotically nonexpansive mappings. Bull. Korean Math. Soc. 42, 661-670 (2005)

5. Cho, YJ, Zhou, HY, Guo, GT: Weak and strong convergence theorems for three-step iterations with errors for asymptotically nonexpansive mappings. Comput. Math. Appl. 47, 707-717 (2004)

6. Chen, W, Guo, W: Convergence theorems for two finite families of asymptotically nonexpansive mappings. Math. Comput. Model. 54, 1311-1319 (2011)

7. Guo, W, Cho, YJ: On strong convergence of the implicit iterative processes with errors for a finite family of asymptotically nonexpansive mappings. Appl. Math. Lett. 21, 1046-1052 (2008)

8. Schu, J: Weak and strong convergence of fixed points of asymptotically nonexpansive mappings. Bull. Aust. Math. Soc. 43, 153-159 (1991)

9. Zhou, YY, Chang, SS: Convergence of implicit iterative process for a finite family of asymptotically nonexpansive mappings in Banach spaces. Numer. Funct. Anal. Optim. 23, 911-921 (2002)

10. Chidume, CE, Ofoedu, EU, Zegeye, H: Strong and weak convergence theorems for asymptotically nonexpansive mappings. J. Math. Anal. Appl. 280, 364-374 (2003)

11. Wang, L: Strong and weak convergence theorems for common fixed points of nonself asymptotically nonexpansive mappings. J. Math. Anal. Appl. 323, 550-557 (2006)

12. Guo, W, Guo, W: Weak convergence theorems for asymptotically nonexpansive nonself-mappings. Appl. Math. Lett. 24, 2181-2185 (2011)

13. Pathak, HK, Cho, YJ, Kang, SM: Strong and weak convergence theorems for nonself-asymptotically perturbed nonexpansive mappings. Nonlinear Anal. 70, 1929-1938 (2009)

14. Zhou, HY, Cho, YJ, Kang, SM: A new iterative algorithm for approximating common fixed points for asymptotically nonexpansive mappings. Fixed Point Theory Appl. 2007, Article ID 64974 (2007)

15. Sun, ZH: Strong convergence of an implicit iteration process for a finite family of asymptotically quasi-nonexpansive mappings. J. Math. Anal. Appl. 286, 351-358 (2003)

16. Falset, JG, Kaczor, W, Kuczumow, T, Reich, S: Weak convergence theorems for asymptotically nonexpansive mappings and semigroups. Nonlinear Anal. 43, 377-401 (2001)

17. Opial, Z: Weak convergence of successive approximations for nonexpansive mappings. Bull. Am. Math. Soc. 73 591-597 (1967)

18. Osilike, MO, Udomene, A: Demiclosedness principle and convergence theorems for strictly pseudocontractive mappings of Browder-Petryshyn type. J. Math. Anal. Appl. 256, 431-445 (2001)

19. Goebel, K, Kirk, WA: Topics in Metric Fixed Point Theory. Cambridge Studies in Advanced Mathematics, vol. 28. Cambridge University Press, Cambridge (1990)

20. Liu, Z, Feng, C, Ume, JS, Kang, SM: Weak and strong convergence for common fixed points of a pair of nonexpansive and asymptotically nonexpansive mappings. Taiwan. J. Math. 11, 27-42 (2007) 